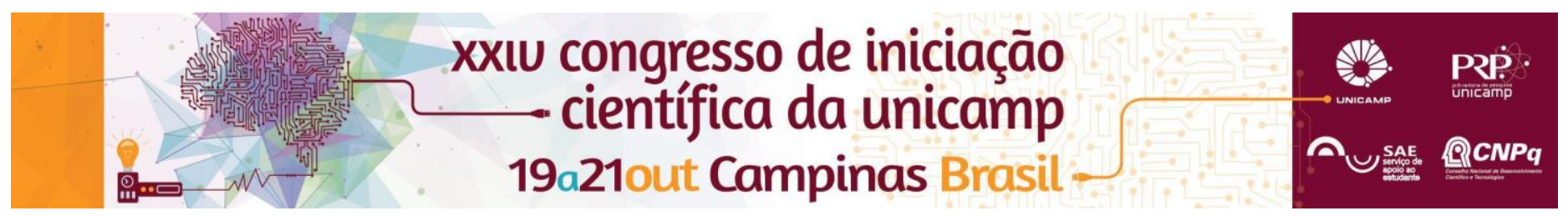

\title{
Caracterização microestrutural e de dureza para compósitos ecologicamente corretos de Al/Eggshells e Al/Gypsum.
}

\section{Erik Geraldini Poloni, Rayane Renie Siqueira Santos.}

\section{Resumo}

O objetivo do trabalho aqui apresentado consiste em analisar a microestrutura de ligas de $\mathrm{Al}($ c.p.)/Eggshell manufaturadas por metalurgia do pó com concentrações mássicas de carbonato de cálcio (eggshell) de $10 \%$ e $20 \%$, mantendo a pressão de compactação em $1200 \mathrm{MPa}$ e sinterizando as amostras a $570^{\circ} \mathrm{C}$ e $640^{\circ} \mathrm{C}$.

\section{Palavras-chave:}

Metalurgia do Pó, Alumínio, Carbonato de Cálcio.

\section{Introdução}

Devido a sua leveza, durabilidade, maleabilidade e outras importantes características, as ligas de alumínio são amplamente utilizadas em diversas indústrias, pois, quando combinadas com outros materiais, podem potencializar os resultados desejados. [1]

Este trabalho trata da liga $\mathrm{Al} / \mathrm{CaCO}_{3}$, um compósito metal-cerâmica, que potencialmente pode ter aplicações nas indústrias aeronáutica e aeroespacial devido ao fato de possuir menor massa especifica quando comparado a outros materiais metálicos. Ocorre também que tais ligas podem apresentar propriedades melhoradas de resistência à tração, dureza, fadiga, módulo de elasticidade, um menor custo relativo e um apelo ambiental. [2]

\section{Resultados e Discussão}

As quatro amostras produzidas foram compactadas a verde com uma pressão de $1200 \mathrm{MPa}$ e então sinterizadas, como indica a Tabela 1.

Tabela 1: Cálculo das densidades. Fonte: Autores.

\begin{tabular}{|c|c|c|c|c|c|}
\hline $\begin{array}{c}\text { Composição } \\
(\% \text { CaC03) }\end{array}$ & $\begin{array}{c}\text { Temp. } \\
\text { Sinterização }\left({ }^{\circ} \mathrm{C}\right)\end{array}$ & $\begin{array}{c}\text { Dens. Teórica } \\
(\mathbf{g} / \mathrm{cm} 3)\end{array}$ & $\begin{array}{c}\text { Massa } \\
\text { Seca }(\mathrm{g})\end{array}$ & $\begin{array}{c}\text { Massa } \\
\text { Molhada (g) }\end{array}$ & $\begin{array}{c}\text { Dens. Exp. } \\
(\mathbf{g} / \mathrm{cm} 3)\end{array}$ \\
\hline 10 & 640 & 2,701 & 1,029 & 0,642 & 2,646 \\
\hline 10 & 570 & 2,701 & 1,140 & 0,713 & 2,659 \\
\hline 20 & 640 & 2,702 & 1,202 & 0,753 & 2,664 \\
\hline 20 & 570 & 2,702 & 1,141 & 0,719 & 2,692 \\
\hline
\end{tabular}

Podemos observar através da Tabela 1 que, no caso das quatro amostras, uma maior temperatura de sinterização $\left(640^{\circ} \mathrm{C}\right)$ resultou em menores valores de densidade para amostras com a mesma composição de $\mathrm{CaCO}_{3}$. Foi possível também analisar os resultados de difração por Raio x das amostras compactadas e após a sinterização. Percebe-se, a partir da Figura 1, que não houve o surgimento de nova fase em nenhuma das amostras.
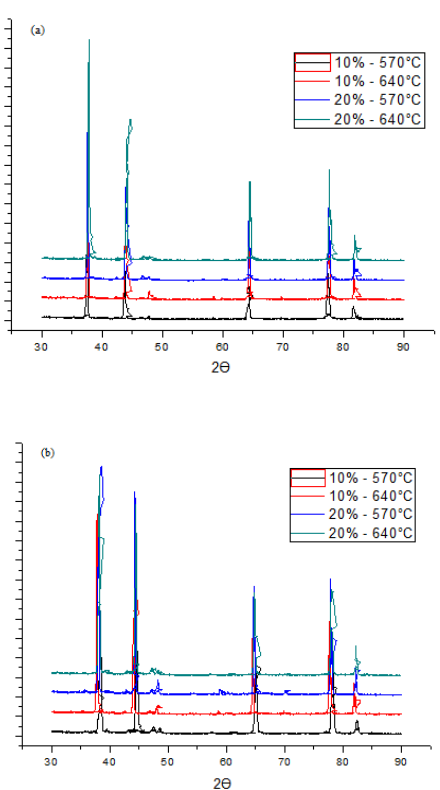

Figura 1: Difractogramas de Raio $X$ das amostras (a) compactadas (b) sinterizadas. Fonte: Autores.

Gráfico 2: Diagrama de Raio-X das amostras compactadas. Fonte: Autores.

\section{Conclusões}

Pretende-se ainda analisar as imagens geradas através do MEV, que darão uma análise maus completa da liga estudada.

\section{Agradecimentos}

Ao professor, orientador e amigo Wislei Riuper Ramos Osório pela crucial motivação para o ingresso na vida acadêmica e à amiga e colega de pesquisa Rayane Renie Siqueira Santos, que muito ajudou na confecção deste trabalho.

\footnotetext{
[1] AUTOR DESCONHECIDO, ABAL Associação Brasileira do Alumínio. Acessado em: http://www.abal.org.br/aluminio/vantagens-doaluminio/

[2] HASSAN S.B., AIGBODION V.S., "Effects of eggshell on the microstructures and properties of $\mathrm{Al}-\mathrm{Cu}-\mathrm{Mg} / \mathrm{eggshell}$ particulate composites", Journal of King Saud University - Engineering Sciences, 27, pp. 49-56, 2015
}

XXIV Congresso de Iniciação Científica da UNICAMP 